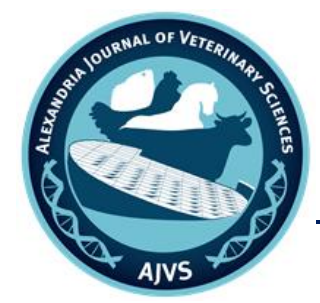

Alexandria Journal of Veterinary Sciences www.alexjvs.com

AJVS. Vol. 66 (1): 100-110 Jul 2020

DOI: 10.5455/ajvs.90846

\title{
Incidence of Contagious Bovine Pleuropneumonia in the Northern Regions of Namibia
}

\author{
Pricilla Mbiri $^{1}$, Erick Kandiwa ${ }^{1}$, Borden Mushonga ${ }^{1}$, Alaster Samkange ${ }^{1 *}$, Alec S. Bishi ${ }^{1}$, Oscar \\ Madzingira ${ }^{1}$, Frank Chitate ${ }^{1}$ \\ ${ }^{1}$ School of Veterinary Medicine, Faculty of Agriculture and Natural Resources, University of Namibia, Private Bag 13301, \\ Pionierspark, Windhoek, Namibia
}

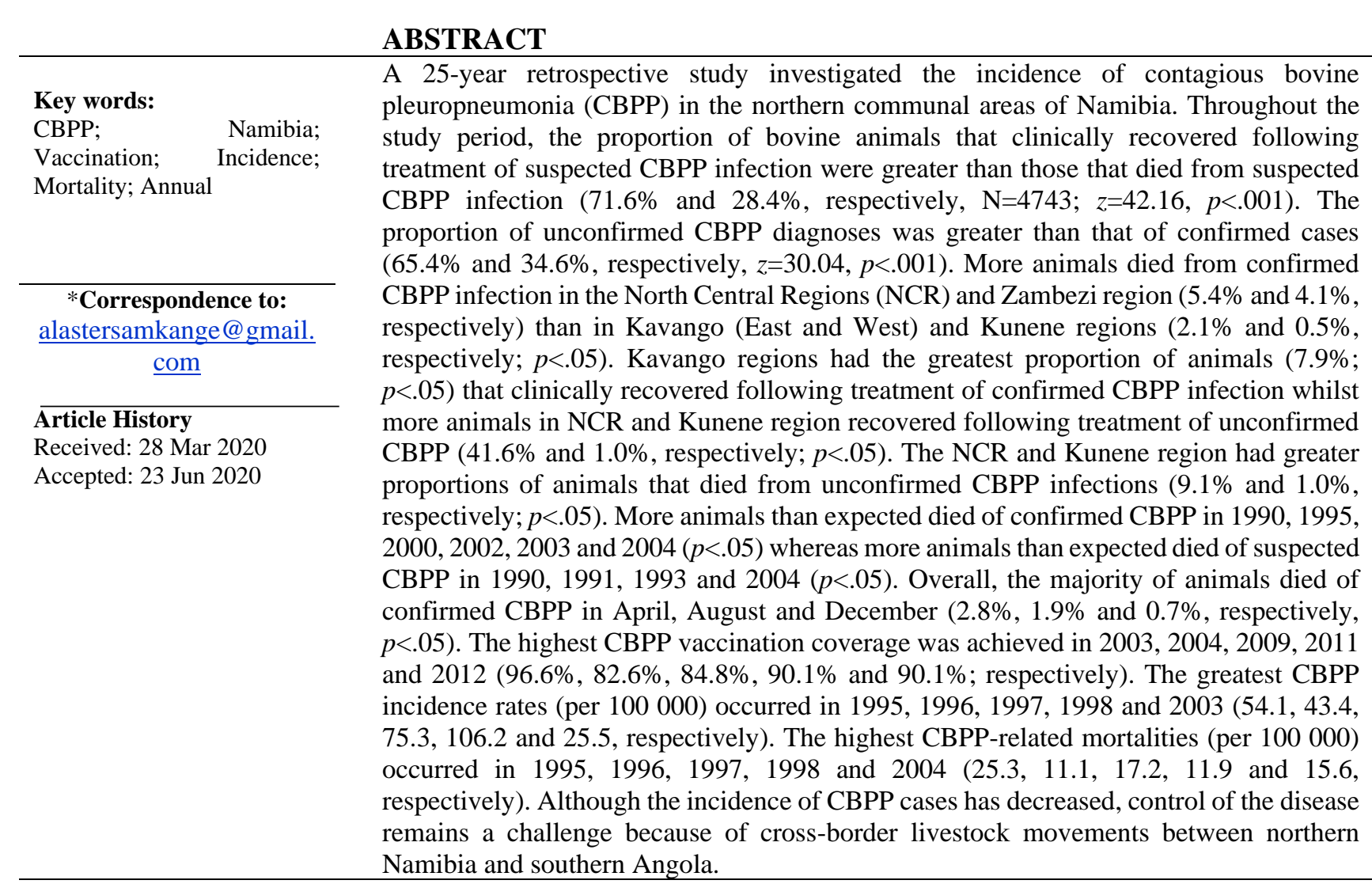

\section{INTRODUCTION}

Contagious bovine pleuropneumonia (CBPP) is an OIE-Listed transboundary, pneumonic disease of cattle, now considered the most important disease since the eradication of rinderpest (Francis et al., 2015; Mamo et al., 2018). The disease is a major challenge to cattle production in sub-Saharan Africa (Amanfu, 2009; Muuka, 2013; Tambi et al., 2006) through its impact on livestock health, loss of revenue by farmers (stock losses) and treatment costs
(Jores et al., 2013; Otte et al., 2004). Affected countries experience revenue losses due to costly disease control and prevention programs, farmer compensation, international trade embargoes and medium to long-term reduction in livestock investment (Abdela and Yune, 2017; Demil, 2017; Nkando et al., 2012).

CBPP is caused by Mycoplasma mycoides subspecies mycoides (Mmm) (Teodoro et al., 2018). The disease is endemic in sub-Saharan Africa (Francis et al., 
2015) where it causes significant morbidity and mortality (Malicha et al., 2017; Muuka, 2013). Age, sex, vicinity to game parks, breed, poor body condition, dry seasons, purpose of rearing (draft power), uncontrolled animal movements and mixed grazing predispose animals to CBPP (Alhaji et al., 2016; Séry et al., 2015). Transmission occurs through aerosols and by direct contact (Lesnoff et al., 2004; Radostits et al., 2007). Lung lesions (sequestra) in subclinical cases are a source of infection for several months to years, especially under stressful conditions (Spickler, 2015). Diagnosis of CBPP, based on clinical signs (fever, anorexia, dyspnoea, polypnea, nasal discharge, coughing, abortion and arthritis), is less reliable due to inconsistency and non-specificity of these signs (Daniel et al., 2017; Hübschle et al., 2006; Schnee et al., 2011). Post mortem findings (pericarditis, peritonitis, lung consolidation, serofibrinous pleuropneumonia and pleural effusions) are more reliable for diagnosis, although, OIE-recommended serological tests (ELISA, complement fixation test and immunoblotting) are commonly used for screening and confirmation (Daniel et al., 2017; Thiaucourt, 2018). Culture and PCR of M. mycoides var mycoides are also important for confirmation of CBPP infections (Amanfu, 2009; Schnee et al., 2011).

Treatment with long acting tetracyclines, fluoroquinolones and macrolides has been attempted, both, in vivo and in vitro with varying degrees of success (Amanfu, 2009; Hübschle et al., 2004; Mitchell et al., 2012; Niang et al., 2010). Treatment is known to create carriers which tend to harbour infections in affected herds (Niang et al., 2010; Yaya et al., 2003). Control of CBPP is achieved through quarantine, movement control, culling, treatment and vaccination; strategies which are very expensive and impractical for farmers in most African countries (Abdela and Yune, 2017; Kairu-Wanyoike et al., 2014; Mwirigi et al., 2016). The role of surveillance, which is backed by strong field and laboratory services, as well as disease control through mass vaccinations, cannot be overemphasised (Demil, 2017). The disease has been eradicated from much of southern Africa including South Africa, Botswana, Zimbabwe (Amanfu, 2009) and much of Zambia and Namibia. The disease has remained endemic in southern Angola (Daniel et al., 2017; Jores et al., 2013) and the northern communal areas of Namibia.

Since the first outbreak of CBPP in Namibia at Warmbad in 1856 (Thiaucourt et al., 2004), sporadic outbreaks have been associated with climatically and politically instigated human movements across the Namibia-Angola border (Van Wolputte, 2015). By 1919 CBPP had been eradicated from all commercial farms south of the Veterinary Cordon Fence (VCF), thus confining the disease to the northern communal areas of Namibia (Schneider, 1994). Vaccination campaigns within communal farmlands in the last 95 years, however, have failed to eradicate CBPP from these areas (Hübschle et al., 2004). In an attempt to control CBPP, the Directorate of Veterinary Services (DVS) in Namibia has used different vaccines and different formulations (Kabete, KH3J strain, V5 strain, T1/SR and T1/44), with varying degrees of success (Schieck et al., 2014). The use of T1/44 since 1997 led to dramatic reduction in the number of CBPP outbreaks. The Kunene, Ohangwena, Omusati and Kavango regions lying north of the VCF and along the border with Angola are at high risk of CBPP outbreaks (Provost et al., 1987).

Several studies have separately reported on Namibian CBPP outbreaks and history in the last three decades (Hübschle et al., 2004; Huebschle et al., 2006; Mbulu et al., 2004; Scacchia et al., 2011; Schneider, 1994; Van Wolputte, 2015). Given the vast economic significance of CBPP, the aim of this study was to investigate and characterize the longitudinal pattern of this disease in Namibia in order to provide critical information for its future control and, possibly, eradication. A similar study over a 20-year duration was undertaken in Ethiopia (Abdela and Yune, 2017).

\section{MATERIALS AND METHODS 2.1 Study area}

This study was based on data gathered from 1990 to 2014 by state veterinarians in the North Central Regions (Omusati, Ohangwena, Oshikoto and Oshana), Kunene, Kavango (later Kavango East and Kavango West) and Caprivi (later Zambezi). Of these regions, Kunene and Oshikoto straddle the Veterinary Cordon Fence (VCF/Red line) which separates the northern regions from the central and southern regions of Namibia. Most farm land in the northern regions is communal and therefore lacks fences to control livestock movements. Mixed grazing and shared watering points are the norm in these communal farm lands. Most farm land in the central and southern regions which are south of the $\mathrm{VCF}$ is commercial, with fences that separate livestock from different farms. The vegetation in Kavango East, Kavango West and Zambezi regions is mostly savanna woodlands with annual precipitation ranging from $500-700 \mathrm{~mm}$. The vegetation in the NCR is Mopane Savanna with annual precipitation of not more than $500 \mathrm{~mm}$.

\subsection{Study animals}


The bovine population in the eight regions (Oshana, Oshikoto, Omusati, Ohangwena, Kavango East, Kavango West, Zambezi and the northern part of Kunene) under study between 1990 and 2014 constituted the animals at risk of contracting CBPP infection during the study period. The annual bovine census figures by the Directorate of Veterinary Services (DVS) in these areas were used as the denominator population at risk.

\subsection{Diagnosis of CBPP}

Preliminary diagnosis of CBPP by DVS was based on clinical signs (fever, anorexia, dyspnoea, polypnea, nasal discharge, coughing, abortion and arthritis) and the epidemiological picture. In some cases, the latex agglutination test was used to confirm diagnosis in the field. In this test, whole blood or serum was mixed with a suspension of killed and stained M. mycoides organisms for the detection of agglutinating antibodies. Laboratory confirmation was carried out, whenever possible, at the Central Veterinary Laboratory (CVL) using the complement fixation test (CFT) to detect antibodies against $M$. mycoides in serum samples. The peroxidaseantiperoxidase (PAP) test was used for histopathological confirmation of CBPP on formalinfixed lung tissues from suspected CBPP cases. Pathological diagnosis of CBPP was based on the accumulation of yellow fluid around uncollapsed lungs and on marbled lungs and pleuritis. Pleural fluid and diseased lungs from suspected CBPP cases were also sent to the CVL for culture, isolation and identification of $M$. mycoides in Mycoplasma Experience (ME) broth and agar medium (Mycoplasma Experience, Reigate, Surrey, United Kingdom). All cattle suspected of CBPP infection were treated with oxytetracycline or tylosin until clinical recovery.

\subsection{Data Collection}

Data was sourced from the Epidemiology section of the Directorate of Veterinary Services in Namibia with the permission of the Chief Veterinary Officer. All the information regarding suspected and confirmed CBPP cases were recorded by the state veterinarian of the district on a disease report form (DRF). The DRF includes information such as name of the farmer, village of origin; crush pen, farming system, history of vaccinations and the number of animals at risk. These forms were submitted to the Epidemiology section where the data was captured and made available in both paper and electronic formats (Fig.1). Departmental annual reports, disease reports to the OIE as well as reports from the Central Veterinary Laboratory were part of the source of the information in this study. A literature search was also conducted with guiding key words such as "CBPP" and "Namibia "on databases such as PubMed, Science Direct and CAB direct.

\begin{tabular}{|c|c|c|c|c|c|c|c|c|c|c|}
\hline $\mathrm{B}$ & $\mathrm{C}$ & D & $E$ & $\mathrm{~F}$ & G & $\mathrm{H}$ & 1 & J & K & $\mathrm{L}$ \\
\hline Date & Year & Months & Farm ID & Mag Dist & Species & Number Sick & Number Dead & Tentative D & ongitude & Latitude \\
\hline $26 / 06 / 01$ & 2001 & 6 & 1 & $4 N C D$ & $\mathrm{BO}$ & 1 & 1 & CBPP & 16.15 & -17.82 \\
\hline $12 / 03 / 01$ & 2001 & 3 & 2 & KAVA & $\mathrm{BO}$ & 5 & 4 & CBPP & 19.21 & -18.20 \\
\hline $25 / 06 / 01$ & 2001 & 6 & 3 & $4 \mathrm{NCD}$ & $\mathrm{BO}$ & 5 & 0 & CBPP & 15.06 & -17.44 \\
\hline $26 / 03 / 01$ & 2001 & 3 & 4 & KAVA & $\mathrm{BO}$ & 3 & 4 & CBPP & 18.23 & -17.86 \\
\hline $01 / 03 / 01$ & 2001 & 3 & 5 & KAVA & $\mathrm{BO}$ & 2 & 6 & CBPP & 18.81 & -17.81 \\
\hline $21 / 09 / 01$ & 2001 & 9 & 6 & $4 \mathrm{NCD}$ & $\mathrm{BO}$ & 5 & 0 & CBPP & 16.07 & -17.80 \\
\hline $11 / 05 / 01$ & 2001 & 5 & 7 & $4 \mathrm{NCD}$ & $\mathrm{BO}$ & 2 & 0 & CBPP & 16.20 & -17.78 \\
\hline $27 / 09 / 01$ & 2001 & 9 & 8 & $4 \mathrm{NCD}$ & $\mathrm{BO}$ & 2 & 0 & CBPP & 16.06 & -17.56 \\
\hline $09 / 05 / 01$ & 2001 & 5 & 9 & KAVA & $\mathrm{BO}$ & 2 & 3 & CBPP & 19.06 & -17.81 \\
\hline $28 / 03 / 01$ & 2001 & 3 & 10 & KAVA & $\mathrm{BO}$ & 3 & 4 & CBPP? & 19.87 & -18.19 \\
\hline $11 / 05 / 01$ & 2001 & 5 & 11 & $4 \mathrm{NCD}$ & $\mathrm{BO}$ & 4 & 0 & CBPP? & 17.66 & -18.50 \\
\hline $22 / 01 / 01$ & 2001 & 1 & 12 & KAVA & $\mathrm{BO}$ & 1 & 1 & CBPP? & 18.81 & -17.81 \\
\hline $23 / 04 / 01$ & 2001 & 4 & 13 & KAVA & $\mathrm{BO}$ & 3 & 8 & CBPP? & 18.19 & -17.69 \\
\hline $02 / 03 / 01$ & 2001 & 3 & 14 & KAVA & $\mathrm{BO}$ & 4 & 8 & CBPP? & 18.81 & -17.81 \\
\hline $15 / 02 / 01$ & 2001 & 2 & 15 & $4 \mathrm{NCD}$ & $\mathrm{BO}$ & 0 & 10 & CBPP? & 15.87 & -18.02 \\
\hline $17 / 05 / 01$ & 2001 & 5 & 16 & $4 \mathrm{NCD}$ & $\mathrm{BO}$ & 7 & 0 & CBPP? & 16.94 & -17.94 \\
\hline $10 / 07 / 01$ & 2001 & 7 & 17 & $4 \mathrm{NCD}$ & $\mathrm{BO}$ & 4 & 1 & CBPP? & 15.08 & -17.57 \\
\hline $04 / 06 / 01$ & 2001 & 6 & 18 & $4 \mathrm{NCD}$ & $\mathrm{BO}$ & 4 & 0 & CBPP? & 16.29 & -18.06 \\
\hline $24 / 01 / 01$ & 2001 & 1 & 19 & KUNE & $\mathrm{BO}$ & 1 & 3 & CBPP? & 13.27 & -17.43 \\
\hline
\end{tabular}

Fig. 1. Example of Data Sheet from an area

\subsection{Statistical analysis}

The Shapiro-Wilk test confirmed that the study population, over the 25 -year study period, had a normal distribution $(\mathrm{W}=0.95)$. The Chi-square test and post hoc adjusted residuals was then performed to test the dependence of four categories (sick animals with confirmed CBPP infection, dead animals with confirmed CBPP infection, sick animals 
with unconfirmed CBPP infection and dead animals with unconfirmed CBPP infections) on the year, month and region. In this study, an outbreak of CBPP was defined as a laboratory confirmed case and a suspected outbreak as a clinically suspicious case for which no samples were submitted for laboratory confirmation. The analysed data excludes all suspected cases that were confirmed negative following further investigation. The annual CBPP incidence and mortality rates for the overall study area and for the four regions were separately determined at $95 \%$ confidence level. The $Z$-test for comparison of proportions was also used at $95 \%$ confidence level. The Statistical Package for Social Sciences (SPSS) version 25 was used for Chi-square analysis and Microsoft Excel 2013 was used for determination of CBPP incidence and mortality rates.

\section{RESULTS}

The results of this study are reported in four parts; zscores and significance of the comparison of proportions of unconfirmed and confirmed cases, the Chi-square test results (with post hoc adjusted residuals) from tests for independence/dependence of sick and dead cases according to months, years and regions, the annual incident rates of CBPP and resulting mortality rates and the spatial distribution of foci of CBPP cases throughout the study period.
As shown in Table 1, a greater proportion of CBPP cases were not confirmed $(65.4 \%, \mathrm{~N}=4743 ; \mathrm{z}=30.04$, $\mathrm{p}<0.001$ ), whilst a greater proportion of CBPP confirmed were successfully treated $(71.6 \%$, $\mathrm{N}=4743 ; \mathrm{z}=42.16, \mathrm{p}<0.001)$. The overall proportion of CBPP suspected cases with confirmed disease that died $(12.1 \%)$ and that of sick bovines with unconfirmed CBPP infection (49.1\%) were greater than expected $[\mathrm{X} 2(1, \mathrm{~N}=4743)=52.46, \mathrm{p}<0.05]$.

As shown in Table 2, the distribution of animal sickness and death due to confirmed/unconfirmed CBPP were dependent on the region; $\mathrm{X} 2(9, \mathrm{~N}=4743)$ $=964.57, \mathrm{p}<0.001$. The proportion of animals that died from confirmed CBPP were greater in the NCR and Zambezi (5.4\% and $4.1 \%$, respectively; $\mathrm{p}<0.05$ ) than in Kavango (East and West combined) and Kunene, whilst those that died from unconfirmed CBPP infections were greater in the NCR and Kunene $(9.1 \%$ and $1.0 \%$, respectively; $\mathrm{p}<0.05)$. Animals that got sick and recovered from confirmed CBPP infections were greatest in Kavango (East \& West) $(7.9 \%$; $\mathrm{p}<0.05)$ whilst those that got sick and recovered from unconfirmed CBPP infections were greater in the NCR and northern Kunene $(41.6 \%$ and $1.0 \%$, respectively; $p<0.05)$ than in the rest of the regions under study.

Table 1: The number and proportion of cattle that died or became sick from confirmed or unconfirmed CBPP infections.

\begin{tabular}{llll}
\hline \multicolumn{4}{c}{ Condition of animals } \\
\hline Diagnostic status & $\begin{array}{l}\text { Number of } \\
\text { sick animals }(\%)\end{array}$ & $\begin{array}{l}\text { Number of } \\
\text { dead animals }(\%)\end{array}$ & Total (\%) \\
\hline Confirmed CBPP & $1068(22.5)$ & $572(12.1)^{*}$ & $\mathbf{1 6 4 0}(\mathbf{3 4 . 6})$ \\
Unconfirmed CBPP & $2330(49.1)^{*}$ & $773(16.3)$ & $\mathbf{3 1 0 3}(\mathbf{6 5 . 4 )}$ \\
\hline Total & $\mathbf{3 3 9 8}(\mathbf{7 1 . 6})$ & $\mathbf{1 3 4 5}(\mathbf{2 8 . 4})$ & $\mathbf{4 7 4 3 ( 1 0 0 . 0 )}$ \\
\hline
\end{tabular}

*These values were significantly greater than expected since $p<0.05$

Table 2: The 25-year categorical distribution of CBPP cases according to region

\begin{tabular}{lccccc}
\hline Region & $\begin{array}{c}\text { CBPP } \\
\text { confirmed sick } \\
(\boldsymbol{\%})\end{array}$ & $\begin{array}{c}\text { CBPP } \\
\text { confirmed } \\
\text { dead (\%) }\end{array}$ & $\begin{array}{c}\text { CBPP } \\
\text { suspected sick } \\
(\boldsymbol{\%})\end{array}$ & $\begin{array}{c}\text { CBPP } \\
\text { suspected } \\
\text { dead (\%) }\end{array}$ & Total (\%) \\
\hline NCR & $438(9.2)$ & $257(5.4)^{*}$ & $1971(41.6)^{*}$ & $433(9.1)^{*}$ & $3099(65.3)$ \\
Zambezi & $199(4.2)$ & $193(4.1)^{*}$ & $130(2.7)$ & $93(2.0)$ & $615(13.0)$ \\
Kavango & $375(7.9)^{*}$ & $98(2.1)$ & $181(3.8)$ & $198(4.2)$ & $852(18.0)$ \\
Kunene & $56(1.2)$ & $24(.5)$ & $48(1.0)^{*}$ & $49(1.0)^{*}$ & $177(3.7)$ \\
\hline Total & $\mathbf{1 0 6 8}(\mathbf{2 2 . 5})$ & $\mathbf{5 7 2 ( 1 2 . 1 )}$ & $\mathbf{2 3 3 0}(\mathbf{4 9 . 1 )}$ & $\mathbf{7 7 3 ( 1 6 . 3 )}$ & $\mathbf{4 7 4 3 ( 1 0 0 . 0 )}$ \\
\hline
\end{tabular}

*These values were significantly greater than expected since $p<0.05$

As shown in Table 3, the distribution of bovine sickness and death due to confirmed/unconfirmed CBPP were dependent on the year; X2 $(72, \mathrm{~N}=4743)$ $=2973.82, \mathrm{p}<0.0001$. The overall annual proportions of sick animals with confirmed CBPP infections were greater than in 1992, 2000, 2002, 2003, 2005, 2008 and 2009, $(\mathrm{p}<0.05)$ than in the other years. The overall proportion of dead animals with confirmed 
CBPP infections were greater in 1990, 1995, 2000, 2002, 2003 and $2004(p<0.05)$ than in the other years. The overall annual proportions of sick animals with unconfirmed CBPP infections were greater than expected in 1996, 1997 and 1998 ( $\mathrm{p}<0.05)$. The overall annual proportions of dead animals with unconfirmed CBPP infections were greater than expected in 1990, 1991, 1993 and 2004 ( $\mathrm{p}<0.05)$. As shown in Table 4, the distribution of animal sickness and death due to confirmed/unconfirmed CBPP were varied with the month; $X^{2}(33, \mathrm{~N}=4743)=920.05$, $p<0.001$.

Throughout the study period, the proportion of animals that recovered from confirmed CBPP infections were more than expected in the months of January, August, October and December (6.3\%, $3.4 \%, 1.0 \%$ and $.8 \%$; respectively) whilst those that died from confirmed CBPP infections were more than expected in April, August and December (2.8\%,
$1.9 \%$ and $.7 \%$; respectively). The proportion of animals that recovered from unconfirmed CBPP infections were more than expected in the months of February, June and September (8\%, 6.9\% and 1.6\%; respectively) whilst those that died from unconfirmed CBPP infections were more than expected in the months of March, July and November (4\%, $2 \%$ and 1.5\%; respectively). As shown in Table 5 , the highest levels of overall vaccine coverage were achieved in 2003, 2004, 2009, 2011 and 2012 (96.6\%, 82.6\%, $84.8 \%, \quad 90.1 \%$ and $90.1 \%$; respectively). The highest CBPP incidence rates (per 100 000) occurred in 1995, 1996, 1997, 1998 and 2003 (54.1, 43.4, 75.3, 106.2 and 25.5; respectively). The highest CBPP-related mortality (per 100 000) occurred in 1995, 1996, 1997, 1998 and 2004 (25.3, 11.1, 17.2, 11.9 and 15.6; respectively).

Table 3: The 25-year categorical distribution of CBPP cases according to year

\begin{tabular}{|c|c|c|c|c|c|}
\hline Year & $\begin{array}{c}\text { Confirmed } \\
\text { CBPP sick (\%) }\end{array}$ & $\begin{array}{c}\begin{array}{c}\text { Confirmed CBPP } \\
\text { dead }(\%)\end{array} \\
\end{array}$ & $\begin{array}{c}\text { Suspected CBPP } \\
\text { sick }(\%)\end{array}$ & $\begin{array}{c}\text { Suspected CBPP } \\
\text { dead }(\%)\end{array}$ & Total $(\%)$ \\
\hline 1990 & $1(0.02)$ & $13(0.27)^{*}$ & $3(0.06)$ & $15(0.32)^{*}$ & $32(0.67)$ \\
\hline 1991 & $18(0.38)$ & $8(0.17)$ & $9(0.19)$ & $34(0.72)^{*}$ & $69(1.45)$ \\
\hline 1992 & $233(4.91)^{*}$ & $10(0.21)$ & $16(0.34)$ & $4(0.08)$ & $263(5.55)$ \\
\hline 1993 & $33(0.70)$ & $8(0.17)$ & $30(0.63)$ & $49(1.03)^{*}$ & $120(2.53)$ \\
\hline 1994 & $15(0.32)$ & $4(0.08)$ & $25(0.53)$ & $1(0.02)$ & $45(0.95)$ \\
\hline 1995 & $103(2.17)$ & $103(2.17)^{*}$ & $124(2.61)$ & $96(2.02)$ & $426(8.98)$ \\
\hline 1996 & $10(0.21)$ & $5(0.11)$ & $276(5.82) *$ & $93(1.96)$ & $384(8.10)$ \\
\hline 1997 & 104 (2.19) & $24(0.51)$ & $423(8.92)^{*}$ & $132(2.78)$ & $683(14.40)$ \\
\hline 1998 & $7(0.15)$ & $12(0.25)$ & $931(19.63)^{*}$ & $106(2.23)$ & $1056(22.26)$ \\
\hline 1999 & $1(0.02)$ & $0(0.00)$ & $27(0.57)$ & $7(0.15)$ & $35(0.74)$ \\
\hline 2000 & $75(1.58)^{*}$ & $69(1.45)^{*}$ & $56(1.18)$ & $23(0.48)$ & $223(4.70)$ \\
\hline 2001 & $22(0.46)$ & $18(0.38)$ & $102(2.15)$ & $45(0.95)$ & $187(3.94)$ \\
\hline 2002 & $60(1.27)^{*}$ & $36(0.76)^{*}$ & $10(0.21)$ & $8(0.17)$ & $114(2.40)$ \\
\hline 2003 & $152(3.20)^{*}$ & $92(1.94)^{*}$ & $11(0.23)$ & $6(0.13)$ & $261(5.50)$ \\
\hline 2004 & $34(0.72)$ & $104(2.19)^{*}$ & $72(1.52)$ & $76(1.60)^{*}$ & $286(6.03)$ \\
\hline 2005 & $77(1.62)^{*}$ & $25(0.53)$ & $58(1.22)$ & $14(0.30)$ & 174 (3.67) \\
\hline 2006 & $12(0.25)$ & $6(0.13)$ & $53(1.12)$ & $7(0.15)$ & 78 (1.64) \\
\hline 2007 & $5(0.11)$ & $0(0.00)$ & $5(0.11)$ & $4(0.08)$ & $14(0.30)$ \\
\hline 2008 & $11(0.23)^{*}$ & $2(0.04)$ & $0(0.00)$ & $0(0.00)$ & $13(0.27)$ \\
\hline 2009 & $27(0.57)^{*}$ & $0(0.00)$ & $3(0.06)$ & $2(0.04)$ & $32(0.67)$ \\
\hline 2010 & $13(0.27)$ & $1(0.02)$ & $20(0.42)$ & $11(0.23)$ & $45(0.95)$ \\
\hline 2011 & $15(0.32)$ & $5(0.11)$ & $18(0.38)$ & $2(0.04)$ & $40(0.84)$ \\
\hline 2012 & $14(0.30)$ & $6(0.13)$ & $12(0.25)$ & $1(0.02)$ & $33(0.70)$ \\
\hline 2013 & $26(0.55)$ & $21(0.44)$ & $43(0.91)$ & $33(0.70)$ & $123(2.59)$ \\
\hline 2014 & $0(0.00)$ & $0(0.00)$ & $3(0.06)$ & $4(0.08)$ & $7(0.15)$ \\
\hline Total & $1068(22.52)$ & $572(12.06)$ & 2330 (49.13) & $773(16.30)$ & $4743(100.00)$ \\
\hline
\end{tabular}


*values were significantly greater than expected since $p<0.05$

Table 4: The 25-year categorical distribution of CBPP cases according to month

\begin{tabular}{llllll}
\hline Month & $\begin{array}{l}\text { Confirmed } \\
\text { CBPP sick (\%) }\end{array}$ & $\begin{array}{l}\text { Confirmed } \\
\text { CBPP dead (\%) }\end{array}$ & $\begin{array}{l}\text { Suspected } \\
\text { CBPP sick (\%) }\end{array}$ & $\begin{array}{l}\text { Suspected } \\
\text { CBPP dead (\%) }\end{array}$ & Total (\%) \\
\hline January & $301(6.3)^{*}$ & $77(1.6)$ & $167(3.5)$ & $48(1.0)$ & $\mathbf{5 9 3}(\mathbf{1 2 . 5})$ \\
February & $67(1.4)$ & $54(1.1)$ & $380(8.0)^{*}$ & $55(1.2)$ & $\mathbf{5 5 6}(\mathbf{1 1 . 7})$ \\
March & $143(3.0)$ & $23(0.5)$ & $375(7.9)$ & $189(4.0)$ & $\mathbf{7 3 0 ( 1 5 . 4 )}$ \\
April & $93(2.0)$ & $134(2.8)^{*}$ & $286(6.0)$ & $106(2.2)$ & $\mathbf{6 1 9}(\mathbf{1 3 . 1})$ \\
May & $76(1.6)$ & $65(1.4)$ & $216(4.6)$ & $72(1.5)$ & $\mathbf{4 2 9}(\mathbf{9 . 0})$ \\
June & $61(1.3)$ & $38(0.8)$ & $325(6.9)^{*}$ & $58(1.2)$ & $\mathbf{4 8 2}(\mathbf{1 0 . 2})$ \\
July & $45(0.9)$ & $18(0.4)$ & $123(2.6)$ & $93(2.0)$ & $\mathbf{2 7 9}(\mathbf{5 . 9})$ \\
August & $159(3.4)^{*}$ & $88(1.9)^{*}$ & $180(3.8)$ & $40(0.8)$ & $\mathbf{4 6 7}(\mathbf{9 . 8})$ \\
September & $10(0.2)$ & $9(0.2)$ & $76(1.6)^{*}$ & $21(0.4)$ & $\mathbf{1 1 6}(\mathbf{2 . 4})$ \\
October & $47(1.0)^{*}$ & $21(0.4)$ & $40(0.8)$ & $12(0.3)$ & $\mathbf{1 2 0}(\mathbf{2 . 5})$ \\
November & $28(0.6)$ & $12(0.3)$ & $150(3.2)$ & $70(1.5)$ & $\mathbf{2 6 0}(\mathbf{5 . 5})$ \\
December & $38(0.8)^{*}$ & $33(0.7)^{*}$ & $12(0.3)$ & $9(0.2)$ & $\mathbf{9 2}(\mathbf{1 . 9})$ \\
\hline Total & $\mathbf{1 0 6 8}(\mathbf{2 2 . 5})$ & $\mathbf{5 7 2}(\mathbf{1 2 . 1})$ & $\mathbf{2 3 3 0}(\mathbf{4 9 . 1})$ & $\mathbf{7 7 3}(\mathbf{1 6 . 3})$ & $\mathbf{4 7 4 3}(\mathbf{1 0 0 . 0})$ \\
\hline
\end{tabular}

*values were significantly greater than expected since $p<0.05$.

\section{DISCUSSION}

As shown in Table 1, the overall annual proportions of sick animals with unconfirmed CBPP infections were greater than expected in 1996, 1997 and 1998 $(p<0.05)$ and the overall annual proportions of dead animals with unconfirmed CBPP infections were greater than expected in 1990, 1991, 1993 and 2004 $(p<0.05)$. Many samples were not confirmed in the laboratory and diagnosis was thus primarily based on clinical signs. This may be attributed to a low veterinary service coverage and a lack of awareness of the disease among farmers. Prior to, and soon after Namibia's independence in 1990, the veterinary service in the northern parts of the country was very low due to limited numbers of DVS personnel. The Northern Central Regions (NCR) which included Oshana, Oshikoto, Ohangwena and Omusati were serviced by state veterinarians based in distant regions. Coupled with inadequate resources, few samples were therefore collected for laboratory diagnosis. In addition, the veterinary pharmaceutical supply chain (Yansambou et al., 2018) was not efficient. With time, the DVS capacity improved greatly and each region in the NCR had two veterinarians with para-veterinary supporting staff which improved CBPP and other livestock disease diagnoses and reporting. The improvement of veterinary services capacity as well as better CBPP mass vaccination coverage could explain the decrease in overall annual proportions and incidence of animals with confirmed CBPP infections observed in the years 2000, 2002, 2003, 2005, 2008 and 2009 up to 2014. A number of studies have pointed out the importance of awareness of the disease among farmers for disease control. The effect of the availability of improved veterinary infrastructure, adequate veterinary personnel, increased vaccination coverage and treatment have been emphasized by other studies as the keys for the control of the disease (Alemayehu et al., 2015; Kairu-Wanyoike et al., 2014). A strong surveillance system can only be achieved with the backing of a strong veterinary field and laboratory service (Demil, 2017). In any case, other studies have reported a positive link between region of origin and the risk of infection with CBPP (Mohamed, 2016). 
Table 5: The 25-year CBPP incidence and mortality rates according to year

\begin{tabular}{ccccccc}
\hline Year & Census & $\begin{array}{c}\text { Vaccine } \\
\text { coverage }(\%)\end{array}$ & $\begin{array}{c}\text { Total CBPP } \\
\text { cases }\end{array}$ & $\begin{array}{c}\text { CBPP Incidence } \\
\text { rate/100 000 }\end{array}$ & $\begin{array}{c}\text { 95\% C. I. } \\
\text { CBPP-related } \\
\text { mortality/100 000 }\end{array}$ \\
\hline 1990 & 639223 & - & 32 & 5 & $3.4-7.1$ & 4.38 \\
1991 & 702075 & - & 69 & 9.8 & $7.6-12.4$ & 5.98 \\
1992 & 711635 & - & 263 & 37 & $32.6-41.7$ & 1.97 \\
1993 & 627305 & - & 120 & 19.1 & $15.9-22.9$ & 9.09 \\
1994 & 659532 & - & 45 & 6.8 & $5-9.1$ & 0.76 \\
1995 & 787780 & - & 426 & $54.1^{*}$ & $49.1-59.5$ & $25.3 *$ \\
1996 & 885279 & - & 384 & $43.4^{*}$ & $39.1-47.9$ & $11.1^{*}$ \\
1997 & 906634 & - & 683 & $75.3 *$ & $69.8-81.2$ & $17.2^{*}$ \\
1998 & 994235 & - & 1056 & $106.2^{*}$ & $99.9-112.8$ & $11.9 *$ \\
1999 & 1080099 & - & 35 & 3.2 & $2.3-4.5$ & 0.65 \\
2000 & 1263598 & - & 223 & 17.6 & $15.4-20.1$ & 7.28 \\
2001 & 1255228 & 58.0 & 187 & 14.9 & $12.8-17.2$ & 5.02 \\
2002 & 1105598 & 73.9 & 114 & 10.3 & $8.5-12.4$ & 3.98 \\
2003 & 1022206 & $96.6^{*}$ & 261 & $25.5 *$ & $22.5-28.8$ & 9.59 \\
2004 & 1152293 & $82.6^{*}$ & 286 & 24.8 & $22-27.9$ & $15.6 *$ \\
2005 & 1185967 & 76.4 & 174 & 14.7 & $12.6-17$ & 3.29 \\
2006 & 1263203 & 80.4 & 78 & 6.2 & $4.9-7.7$ & 1.03 \\
2007 & 1099297 & 41.7 & 14 & 1.3 & $.7-2.1$ & 0.36 \\
2008 & 1161547 & 76.7 & 13 & 1.1 & $.6-1.9$ & 0.17 \\
2009 & 1047687 & $84.8^{*}$ & 32 & 3.1 & $2.1-4.3$ & 0.19 \\
2010 & 1249107 & 79.87 & 45 & 13.6 & $2.6-4.8$ & 0.96 \\
2011 & 1233994 & $90.1 *$ & 40 & 3.2 & $2.3-4.4$ & 0.57 \\
2012 & 1342804 & $90.1^{*}$ & 33 & 2.5 & $1.7-3.5$ & 0.52 \\
2013 & 1502583 & 77.4 & 123 & 8.2 & $6.8-9.8$ & 3.59 \\
2014 & 1525603 & - & 7 & 0.5 & $.2-0.9$ & 0.26 \\
\hline
\end{tabular}

*The greatest five values within each column; - data not available

The proportions of animals that died from confirmed CBPP were greater than expected in the NCR and Zambezi $(5.4 \%$ and $4.1 \%$, respectively) than in Kavango and Kunene (Table 2). The high proportion of animals that died in the NCR could be attributed to low veterinary service capacity at the time. The launch of the Namibian Livestock Identification and Traceability System (NamLITS) and its enforcement after 2011 enabled individual cattle identification and facilitated effective disease outbreak management. Movement restriction enforcement thus became easier since NamLITS was implemented and the NCR was no longer being treated as one epidemiological unit (Nicholas et al., 2006).

In 2003 (Table 3) an outbreak of CBPP occurred in the Zambezi region after 60 years of relative "silence". This outbreak caught DVS unprepared and resulted in massive losses of cattle in the region. The outbreak was caused by an introduction of cattle from
Zambia (Huebschle et al., 2004; Nicholas et al., 2006). A similar situation of a sudden upsurge of CBPP after a long lull was reported elsewhere (Masiga et al., 1996) whilst other authors have recommended that effective disease surveillance was essential to avoid re-introduction of CBPP (Alemayehu et al., 2015).

Animals that got sick and recovered from confirmed CBPP infections were greatest in Kavango (7.9\%) (Table 2). In this region, the Namibia-Angola border has a physical barrier in the form of the Kavango River, unlike in other regions bordering Angola. This makes it difficult for cattle to freely cross between the two countries during the rainy season. Imposing movement control as a strategy in trying to control an outbreak is feasible in this region. Together with antibiotic treatment, these could be the reasons why Kavango had the higher observed overall recovery rate following treatment of CBPP. In a study 
conducted in the Zambezi region, it was discovered that the off-label use of some antimicrobials such as danofloxacin could greatly reduce the transmission of M. mycoides subsp. mycoides to in-contact animals (Hübschle et al., 2004). It is possible that danofloxacin was effective against $M$. mycoides subsp. mycoides or, alternatively, it cleared the animals of concurrent infections rendering the animals less susceptible to CBPP.

The distribution of animal sickness and death due to confirmed/unconfirmed CBPP were dependent on the month (Table 4). Throughout the study period, the proportion of animals that recovered from confirmed CBPP infections were more than expected in the months of January (6.3\%.) Around this time there is plenty of grazing in the NCR, animals are in a good condition to fight infection, and also increasing their likelihood of recovering from concurrent illnesses. Studies have confirmed the negative link between body condition score and susceptibility to CBPP (Atnafie et al., 2015; Geresu et al., 2017).

The proportion of animals that died from confirmed CBPP infections were more than expected in April, August and December $(2.8 \%, 1.9 \%$ and .7\%; respectively). Most regions in the NCR are generally dry with little to no grazing from August to December. The dry season has been identified as a risk factor in a number of studies (Geresu et al., 2017; Kassaye and Molla, 2013; Mamo et al., 2018). The lack of good grazing and water forces animals to move long distances, in search of better grazing and water, sometimes deep into Angola where CBPP is endemic (Daniel et al., 2017; Jores et al., 2013). The mixing of cattle with other herds increases the risk of infection with CBPP (Alhaji, 2011; Alhaji et al., 2016). In addition, trekking of cattle on hoof in groups would have increased chances of infection, probably through increased stress (Spickler, 2015). The presence of concurrent diseases on the northern side of the VCF can predispose cattle to CBPP infection (Thomson, 2005). In addition to this, animals in these areas were more confined to 'favourite' grazing areas and watering points and thus facilitating the transmission of CBPP in these crowded pastures (Thiaucourt, 2018). Humans and their livestock living along the Namibia-Angola border, for example, often freely move across the border for socio-political reasons, trade, grazing and water in both directions (Mbiri, 2017). Local crossborder movement is accepted by both countries thus further exacerbating the risk of spreading CBPP (Mbiri, 2017; Provost et al., 1987).

The proportion of animals that recovered from unconfirmed CBPP infections were more than expected in the months of February, June and
September $(8 \%, 6.9 \%$ and $1.6 \%$, respectively) whilst those that died from confirmed CBPP infections were more than expected in the months of March, July and November $(4 \%, 2 \%$ and $1.5 \%$, respectively). This may have been due to the fact that the climate may weaken the host and thus increase its susceptibility to infection or provide host conditions favourable for the survival of the infectious agent (Thrusfield and Christley, 2018).

It has been reported that vaccination is the most realistic option for CBPP control in Namibia at the moment (Muinde, 2014; Nicholas et al., 2006). However, the live-attenuated M. mycoides subsp. mycoides (T1/44) strain, which confers only short term immunity of about 8 months to 1 year, has low efficacy and may result in adverse reactions (Mwirigi et al., 2016). Another challenge is that the T1/44 vaccine strain from the Botswana Vaccine Institute (BVI), which was used in Namibia, must be used within one hour after reconstitution. It is manufactured as 100-dose vials which might not be finished within the prescribed one hour, especially in situations of low cattle turnout during mass vaccination campaigns leading to the inevitable use of non-viable vaccine. Despite the good vaccination coverage of $80-90 \%$ that has been achieved by the DVS in these regions, CBPP vaccines used have been known to achieve only 30-60\% protection after primary vaccination (Wesonga and Thiaucourt, 2000). It has been speculated that the low vaccine titres result from the poor vaccine manufacturing standards in African countries, improper management of the cold chain (especially in hot climates like Namibia) and $\mathrm{pH}$ changes that occur between reconstitution and administration of the vaccine (March, 2004).

Namibia tried at least five different vaccine formulations (the Kabete vaccine, the KH3J strain vaccine, the V5 strain vaccine, the T1/SR vaccine and the T1/44 vaccine) for CBPP control with varying degrees of success. The last switch to the T1/44 vaccine which was implemented in 1997 drastically reduced the number of outbreaks. This may explain why the highest CBPP incidence rates and related mortalities were recorded before 1997. From our results, the years that received the best vaccine coverage were 2003, 2004, 2009, 2011 and 2012 (Table 5). It has been demonstrated in previous studies that adverse post-vaccination reactions (Thiaucourt et al., 2004) and even residual pathogenic infections arising from vaccination has discouraged farmers from participating in vaccination programmes (Mbulu et al., 2004; Scacchia et al., 2011; Teshale, 2005). Despite the effort from the DVS to conduct intensive vaccination 
campaigns, the attitude from the farmers contributed to the low turnout during such campaigns before 2003.

A question still remains as to why there are isolated outbreaks despite good vaccination coverage. Apart from the loss of viability of the current vaccine that occurs in the time between reconstitution and administration of the vaccine, accompanied by the lower levels of protection, there is a need to look at the inconsistencies surrounding the selection of animals for vaccination. According to the CBPP vaccine manufacturer (BVI), calves less than two months old should not be vaccinated. One study showed that unvaccinated calves, between the ages of 2 and 8 months in vaccinated herds, are equally susceptible to CBPP infection (Muuka, 2013). Thus the probability of calves getting the infection from adult cattle within the herd is very high (Muuka, 2013). Unlike other traditional set-ups in subSaharan Africa where calves are usually tethered within the homestead whilst adult cattle are taken for grazing to save them from exhaustion suffered by older animals walking long distances in search of grazing and water as well as interacting with herds from other households, Namibian cattle generally graze together with their calves. This continuously exposes these calves to CBPP which often enough is facilitated by the lack of solid immunity (Muuka, 2013).

Another reason for isolated outbreaks despite good vaccination coverage is uncontrolled movements of cattle between northern Namibia and southern Angola where CBPP is endemic. These livestock movements result in mixing of some recently vaccinated but not yet protected animals with infected animals. In the Zambezi region where there is no uncontrolled livestock movement across the borders, isolated outbreaks of CBPP have not been reported since the last major outbreaks of 2003 and 2004.

\section{ACKNOWLEDGEMENTS}

The authors wish to thank the Directorate of Veterinary Services in Namibia for availing the data which was used in this research.

\section{REFERENCES}

Abdela, N., Yune, N. 2017. Seroprevalence and Distribution of Contagious Bovine Pleuropneumonia in Ethiopia: Update and Critical Analysis of 20 Years (1996-2016) Reports. Front. Vet. Sci. 4: 1-8.

Alemayehu, G., Leta, S., Hailu, B. 2015. Sero-prevalence of Contagious Bovine Pleuropneumonia (CBPP) in bulls originated from Borena Pastoral Area of Southern Ethiopia. Anim. Vet. Sci. 2(6): 213-217.
Alhaji, N.B. 2011. Participatory epizootiology of contagious bovine pleuropneumonia (CBPP) in Niger State, Nigeria. University of Ibadan, Nigeria.

Alhaji, N.B., Babalobi, O.O., Saidu, S. 2016. Using seropositivity to assess geospatial burden of contagious bovine pleuropneumonia on pastoral cattle herds of north-central Nigeria. Pastor. Res. Policy Pract. 6(20): $1-9$.

Amanfu, W. 2009. Contagious bovine pleuropneumonia (lungsickness) in Africa. Onderstepoort J. Vet. Res. 76: 13-17.

Atnafie, B., Goba, H., Sorri, H., Kasaye, S. 2015. SeroPrevalence of Contagious Bovine Pleuropneumonia in Abattoirs at Bishoftu and Export Oriented Feedlots Around Adama. Glob. Vet. 15(3): 321-324.

Daniel, S., Abeledo-Abreu, M., Lobo-Rivero, E. 2017. Seroprevalence of bovine pleuropneumonia in three municipalities of Namibe province, Angola. Rev. Salud Anim. 39(1): 62-67.

Demil, E. 2017. Contagious Bovine Pleuropneumonia: The Epidemiology, Control And Its Economic Impact. World Rural Oberv. 9(4): 21-30.

Francis, M.I., Ejeh, E.F., A, R.M., Egwu, G.O. 2015. Methods of isolation and identification of Mycoplasma species of ruminants in Africa - a review. Bull. Anim. Heal. Prod. Africa 63: 411-431.

Geresu, M.A., Kedir, K., Birhanu, D., Teshome, A. 2017. Sero-epidemiological investigation and risk factors for contagious bovine pleuro pneumonia infection of cattle in Dello Mena and Sawena Districts of Bale Zone, South Eastern Ethiopia. J. Public Heal. Epidemiol. 9(5): 122132.

Hübschle, O., Aschenborn, O., Godinho, K., Nicholas, R. 2006. Control of CBPP - a role for antibiotics? Vet. Rec. 159(14): 464-464.

Hübschle, O., Godinho, K., Rowan, T., Nicholas, R. 2004. Danofloxacin treatment of cattle affected by CBPP. Vet. Rec. 155(13): 403.

Huebschle, O.J.B., Ayling, R.D., Godinho, K., Lukhele, O., Tjipura-Zaire, G., Rowan, T.G., Nicholas, R.A.J. 2006. Danofloxacin (AdvocinTM) reduces the spread of contagious bovine pleuropneumonia to healthy incontact cattle. Res. Vet. Sci. 81(3): 304-309.

Huebschle, O.J.B., Bamhare, C., Tjipura-Zaire, G. 2004. Towards sustainable CBPP control programmes for Africa [WWW Document]. FAO. URL http://www.fao.org/3/y5510e/y5510e0w.htm (accessed 6.16.19).

Jores, J., Mariner, J.C., Naessens, J. 2013. Development of an improved vaccine for contagious bovine pleuropneumonia: An African perspective on challenges and proposed actions. Vet. Res. 44(122): 1-5.

Kairu-Wanyoike, S.W., Kiara, H., Heffernan, C., Kaitibie, S., Gitau, G.K., McKeever, D., Taylor, N.M. 2014. Control of contagious bovine pleuropneumonia: Knowledge, attitudes, perceptions and practices in Narok district of Kenya. Prev. Vet. Med. 115(3-4): 143-156.

Kassaye, D., Molla, W. 2013. Seroprevalence of contagious bovine pleuropneumonia at export quarantine 
centers in and around Adama, Ethiopia. Trop. Anim. Health Prod. 45(1):275-279.

Lesnoff, M., Laval, G., Bonnet, P., Abdicho, S., Workalemahu, A., Kifle, D., Peyraud, A., Lancelot, R., Thiaucourt, F. 2004. Within-herd spread of contagious bovine pleuropneumonia in Ethiopian highlands. Prev. Vet. Med. 64(1):27-40.

Malicha, G., Alemu, S., Aklilu, F., Abraha, A. 2017. Study of Seroprevalence and Associated Risk Factors of Contagious Bovine Pleuropneumonia in Sidama Zone, Southern Ethiopia. J. Vet. Sci. Technol. 8(5).

Mamo, Y., Bitew, M., Teklemariam, T., Soma, M., Gebre, D., Abera, T., Benti, T., Deneke, Y. 2018. Contagious bovine pleuropneumonia: Seroprevalence and risk factors in Western Oromia, Ethiopia. Vet. Med. Int. 2018(1):1-7.

March, J.B. 2004. Improved formulations for existing CBPP vaccines - recommendations for change. Vaccine 22(31-32):4358-4364.

Masiga, W.N., Domenech, J., Windsor, R.S. 1996. Manifestation and epidemiology of contagious bovine pleuropneumonia in Africa. Rev. Sci. Tech. l'OIE 15(4):1283-1308.

Mbiri, P. 2017. A retrospective analysis of the epidemiology of contagious bovine pleuropneumonia in the Northern Communal Areas of Namibia from 2001 to 2013. University of Pretoria.

Mbulu, R.-S., Tjipura-Zaire, G., Lelli, R., Frey, J., Pilo, P., Vilei, E.M., Mettler, F., Nicholas, R.A.J., Huebschle, O.J.B. 2004. Contagious bovine pleuropneumonia (CBPP) caused by vaccine strain T1/44 of Mycoplasma mycoides subsp. mycoides SC. Vet. Microbiol. 98(34):229-234.

Mitchell, J.D., McKellar, Q.A., McKeever, D.J. 2012. Pharmacodynamics of Antimicrobials against Mycoplasma mycoides mycoides Small Colony, the Causative Agent of Contagious Bovine Pleuropneumonia. PLoS One 7(8):e44158.

Mohamed, Z.B. 2016. Epidemiology of contagious bovine pleuropneumonia in Kelantan and Terengganu, Malaysia. Universiti Putra Malaysia.

Muinde, J.N. 2014. The efficacy of conventional and modified contagious bovine pleuropneumonia T1/44 vaccines sixteen months post vaccination. Kenyatta Univ. Kenyatta University.

Muuka, M. 2013. Clinical Cases of Contagious Bovine Pleuropneumonia (CBPP) among Calves in Vaccinated Cattle Herds in Zambia: A Case Study. J. Vet. Sci. Med. Diagn. 2(4):1-4.

Mwirigi, M., Nkando, I., Aye, R., Soi, R., Ochanda, H., Berberov, E., Potter, A., Gerdts, V., Perez-Casal, J., Naessens, J., Wesonga, H. 2016. Experimental evaluation of inactivated and live attenuated vaccines against Mycoplasma mycoides subsp. mycoides. Vet. Immunol. Immunopathol. 169:63-67.

Niang, M., Sery, A., Doucouré, M., Koné, M., N?Diaye, M., Amanfu, W., Thiaucourt, F. 2010. Experimental studies on the effect of long-acting oxytetracycline treatment in the development of sequestra in contagious bovine pleuropneumonia-infected cattle. J. Vet. Med. Anim. Heal. 2(4):35-45.

Nicholas, R.A., Aschenborn, H.K.O., Ayling, R.D., Loria, G.R., Lukhele, O., Tjipura-Zaire, G., Godinho, K., Hübschle, O.J.B. 2006. Effect of Advocin on the elimination of CBPP from the Caprivi region of Namibia, in: In CBPP Control: Antibiotics to the Rescue. Proceedings of FAO-OIE-AU/IBAR-IAEA Consultative Group Meeting on CBPP in Africa. pp. 6-8.

Nkando, I., Ndinda, J., Kuria, J., Naessens, J., Mbithi, F., Schnier, C., Gicheru, M., McKeever, D., Wesonga, H. 2012. Efficacy of two vaccine formulations against contagious bovine pleuropneumonia (CBPP) in Kenyan indigenous cattle. Res. Vet. Sci. 93(2):568-573.

Otte, M.J., Nugent, R., McLeod, A. 2004. Transboundary Animal Diseases: Assessment of socio-economic impacts and institutional responses, Livetock Policy Discussion Paper.

Provost, A., Perreau, P., Breard, A., Le Goff, C., Martel, J.L., Cottew, G.S. 1987. Contagious bovine pleuropneumonia. Rev. Sci. Tech. 6(3):625-679.

Radostits, O.M., Blood, D.C., Gay, C.C. 2007. A text book of diseases of cattle sheep, pig, goats and horses, 10th ed. Bailliere Tindall, London.

Scacchia, M., Tjipura-Zaire, G., Lelli, R., Sacchini, F., Pini, A. 2011. Contagious bovine pleuropneumonia: humoral and pathological events in cattle infected by endotracheal intubation or by exposure to infected animals. Vet. Ital. 47(4):407-413.

Schieck, E., Liljander, A., Hamsten, C., Gicheru, N., Scacchia, M., Sacchini, F., Heller, M., Schnee, C., Sterner-Kock, A., Hlinak, A., Naessens, J., Poole, J., Persson, A., Jores, J. 2014. High antibody titres against predicted Mycoplasma surface proteins do not prevent sequestration in infected lung tissue in the course of experimental contagious bovine pleuropneumonia. Vet. Microbiol. 172(1-2):285-293.

Schnee, C., Heller, M., Jores, J., Tomaso, H., Neubauer, H. 2011. Assessment of a novel multiplex real-time PCR assay for the detection of the CBPP agent Mycoplasma mycoides subsp. mycoides SC through experimental infection in cattle. BMC Vet. Res. 7(47):1-12.

Schneider, H.P. 1994. Animal Health and Veterinary Medicine in Namibia, 1st ed. AGRIVET, Windhoek, Namibia.

Séry, A., Sidibé, C.A.K., Cissé, O., Diallo, M., Koné, M., Waret-Szkuta, A., Roger, F., Thiaucourt, F., Niang, M. 2015. Seroprevalence of contagious bovine pleuropneumonia (CBPP) in Mali. Trop. Anim. Health Prod. 47(2):395-402.

Spickler, A.R. 2015. Contagious Bovine Pleuropneumonia [WWW Document]. Iowa State Univ. Coll. Vet. Med. URL http://www.cfsph.iastate.edu/DiseaseInfo/ factsheets.php.\%0AReferences (accessed 6.16.19).

Tambi, N.E., Maina, W.O., Ndi, C. 2006. An estimation of the economic impact of contagious bovine pleuropneumonia in Africa. Rev. Sci. Tech. 25(3):9991012.

Teodoro, G. Di, Marruchella, G., Provvido, A. Di, Orsini, G., Ronchi, G.F., D’Angelo, A.R., D’Alterio, N., 
Sacchini, F., Scacchia, M. 2018. Respiratory explants as a model to investigate early events of contagious bovine pleuropneumonia infection. Vet. Res. 49(5):1-12.

Teshale, S. 2005. Contagious bovine pleuropneumonia (CBPP) post-vaccinal complication in Ethiopia. Bull. Anim. Heal. Prod. Africa 53(4):242-250.

Thiaucourt, F. 2018. Contagious bovine pleuropnemonia (Infection with Mycoplasma mycoides subsp. mycoides SC), in: Manual of Diagnostic Tests and Vaccines for Terrestrial Animals 2019. OIE, pp. 1097-1112.

Thiaucourt, F., Van Der Lugt, J.J., Provost, A. 2004. Contagious bovine pleuropneumonia, in: Tustin, R.C., Coetzer, J.A.W. (Eds.), Infectious Diseases of Livestock. Oxford University Press Southern Africa, Goodwood, South Africa, pp. 2045-2059.

Thomson, G.R. 2005. Contagious Bovine Pleuropneumonia and Poverty: A Strategy for Addressing the Effects of the Disease in Sub-Saharan Africa. Edinburgh, UK.

Thrusfield, M., Christley, R. 2018. Veterinary epidemiology, 4th ed. John Wiley \& Sons Ltd., Oxford OX4 2DQ, UK.
Van Wolputte, S. 2015. "The natives are clever enough": Contagious bovine pleuropneumonia and the politics of ambiguity in north-west Namibia. Soc. Dyn. 41(1):166183.

Wesonga, H.O., Thiaucourt, F. 2000. Experimental Studies on the Efficacy of T1sr and T1 / 44 Vaccine Strains of Mycoplasma mycoides Subspecies mycoides ( Small Colony ) against a Field Isolate Causing Contagious Bovine Pleuropneumonia in Kenya - Effect of a Revaccination. Rev. Livest. Vet. Med. Trop. 53, 313-318.

Yansambou, M.S., Diallo, A.A., Idi, M., Gagara, H., Haido, A.M., Bada Alambedji, R. 2018. Serological Prevalence of Contagious Bovine Pleuropneumonia in Niger in 2017. Front. Vet. Sci. 5:1-9.

Yaya, A., Wesonga, H., Thiaucourt, F. 2003. Use of longacting tetracycline for CBPP: preliminary results., in: Proceedings of the FAO-OIE-AU/IBAR-IAEA Consultative Group on CBPP Third Meeting. Rome, Italy. 